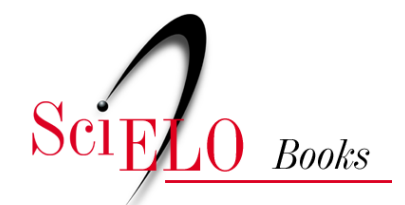

\title{
Histórias do Dr. Wladimir Lobato Paraense (janeiro de 1989)
}

\author{
Virgínia Schall
}

\section{SciELO Books / SciELO Livros / SciELO Libros}

SCHALL, V. Histórias do Dr. Wladimir Lobato Paraense (janeiro de 1989). In: Contos de Fatos: histórias de Manguinhos [online]. Rio de Janeiro: Editora FIOCRUZ, 2001, pp. 25-42. ISBN: 978-857541-614-3. Available from: doi: 10.7476/9788575416143.0005. Also available in ePUB from: http://books.scielo.org/id/hdq6f/epub/schall-9788575416143.epub.

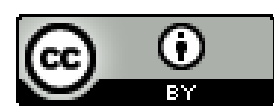

All the contents of this work, except where otherwise noted, is licensed under a Creative Commons Attribution 4.0 International license.

Todo o conteúdo deste trabalho, exceto quando houver ressalva, é publicado sob a licença $\underline{\text { Creative Commons }}$ Atribição 4.0. 


\section{Histórias do Dr. \\ Wladimir Lobato Paraense (janeiro de 1989)}

Ajuda-te e o céu te ajudará.

Bíblia

F stou sentada diante do Dr. Lobato, em sua sala no Pavilhão Adolfo Lutz. Seus olhos azuis me transmitem a emoção dos fatos narrados e eu posso reviver e ver em detalhes as suas aventuras mundo afora, na busca incansável por exemplares raros de moluscos. Em seu talento de naturalista, como hoje se encontram poucos, basta uma ligeira conversa para perceber a sua dedicação, a qual tem permitido desvendar e estruturar a sistemática de um grande grupo zoológico; a marca de sua contribuição para o conhecimento da vida está impressa na descrição e na revisão de múltiplas espécies. Na sala, o tempo parece não existir: a narrativa domina o ambiente e não se percebem as horas passando, embora lá fora a tarde vá sendo engolida pela noite. A mesa transpira cultura: entre livros e pilhas de separatas, dicionários estão à mão para comprovar as raízes gregas ou latinas das palavras. Ele sempre vai atrás do âmago do conhecimento, não sabe se contentar com a superfície das coisas, seu pensamento é um mergulho profundo. Ouvi-lo é aprender saboreando.

Mas vamos a algumas de suas histórias. Duas delas, mais longas, primam pela precisão dos detalhes dos fatos contados com vívida memória e revelam o mais puro feeling sherlockiano do narrador. 


\section{Pensão de Caramujos}

Na década de 40, precisamente entre 1942 e 1945, Dr. Lobato trabalhou, por designação do então diretor do IOC, Dr. Henrique Aragão, em Belo Horizonte, com o propósito de investigar problemas locais. Uma das pesquisas, realizada na Santa Casa, tinha por objetivo investigar a doença chamada fogo selvagem. Naquela época, começou também outro trabalho, visando a identificar focos de Schistosoma mansoni, o parasita causador da esquistossomose. Tratava-se de uma verminose em expansão no Brasil e cada vez mais prevalente entre os mineiros, até mesmo na capital. Mapeou 44 criadouros na cidade, o que descreveu em uma publicação. Depois de passar alguns anos fora de Belo Horizonte, retornou em 1951, revisitou os locais, muitos dos quais haviam desaparecido com a crescente urbanizaçạ̃o da cidade, cobertos por avenidas e novos edifícios. $\mathrm{Na}$ época, o estudante de medicina José Malheiros, que conhecia muito bem a cidade, acompanhava o Dr. Lobato em suas buscas. Tão transformada estava a capital em relação aos mapas originais da prefeitura, que onde pensavam encontrar um pântano deparavam-se com um aterro e construções modernas. Se iam ao encontro de um riacho, encontravam um córrego canalizado por baixo de uma larga avenida. Restavam poucos daqueles 44 pontos anteriormente identificados, e estes poucos ficavam todos na periferia, de modo que o centro da cidade parecia saneado e livre daquela doença. Entretanto... muito não tardou e Dr. Lobato fez uma descoberta inusitada.

Certa vez, à tarde, em hora de lazer, tomando um chope na beira do lago do Parque Municipal, bem no coração da cidade, Dr. Lobato percebeu abaixo do nível d'água uns relevos que logo despertaram seu senso de observação e sua experiência de naturalista. Esboços de conchas, suas antigas conhecidas, insinuavam-se sob a água: seriam caramujos? Dia seguinte, pela manhã bem cedo, antes das 6 horas, para não chamar atenção, chegava ao parque o Dr. Lobato com sua concha metálica perfurada, com longo cabo de madeira, própria para coletar caramujos. Bastaram algumas 
conchadas e lá estava a confirmação de sua suspeita. Não havia mais dúvida: os exemplares graúdos de Biomphalaria glabrata, uma espécie transmissora do parasita causador da esquistossomose, iam surgindo. Foi possível coletar rapidamente mais de cem exemplares. Ao examiná-los sob luz no laboratório, constatou $69 \%$ positivos, eliminando larvas - as cercárias do Schistosoma mansoni. Era um achado que requeria um alerta rápido. Afinal, o lago, de água praticamente parada, era um atraente ponto de lazer, cheio de barquinhos de passeio para as crianças, as quais nunca se contentavam em não se molhar. Em seu ímpeto de jogar pão aos patos e gansos, assim como de tocar nos peixes, estavam sempre a mergulhar mãos e pés nas águas. A presença dos caramujos alertava para o alto risco de contaminação.

Retornou outras vezes com o estudante Malheiros, para coletar mais exemplares, de modo a pesquisar melhor as taxas de infecção por esquistossomose, inoculando camundongos com as cercárias liberadas pelos caramujos e refazendo o ciclo do parasita. Algumas pessoas viram os pesquisadores recolhendo coisas do lago e começaram a perguntar do que se tratava. A curiosidade despertada não tardou a atrair a imprensa. Uma coleta feita pela manhã e já à tarde, por volta das 15 horas, o Malheiros telefona ao Dr. Lobato, informando que o Diário da Tarde estava interessado em fazer uma matéria. No dia seguinte, a reportagem de capa dava destaque: "Pensão de caramujos, paraíso da xistossomose". A partir daí, foi como um rastilho: outros jornais, cartas de leitores, jornalistas solicitando entrevistas etc. Questões políticas logo se misturaram aos fatos. A equipe da prefeitura não admitia aquela denúncia. Um engenheiro de obras da prefeitura, chamado a opinar na imprensa, afirmou que o lugar era isolado e que a água vinha de um poço artesiano, não havendo a menor possibilidade da existência de caramujos ali. Informou ainda que o fundo era cimentado. Como se não bastasse, correu um boato segundo o qual um candidato a prefeito havia pago uma vultosa soma ao Dr. Lobato para que ele colocasse na lagoa os moluscos, só para dizer que limparia a cidade daquele mal. Quem mais se ofendeu foi o próprio pesquisador, comprometido que 
sempre fora com a ética científica e a honestidade. Decidiu desmascarar aqueles políticos oportunistas e não mediu esforços até descobrir tudo.

Dr. Lobato conseguiu mapas do parque no arquivo da prefeitura e passou a coletar pistas que pudessem esclarecer o que de fato estava se passando ali. Uma funcionária da prefeitura, $D$. Irene, conseguiu documentos da obra do lago que revelavam não haver pavimentação. Dr. Lobato confirmou a informação fincando bambus no fundo do lago, os quais perfuraram o solo e saíam enlameados em grande extensão. Para completar, Dr. Lobato mediu a superfície e a vazão do poço artesiano de onde afirmavam vir a água que preenchia o lago. Usou como medida o enchimento de baldes por minuto e concluiu que a vazão do tubo do poço artesiano não era suficiente para completar o volume de água do lago. Utilizando conhecimentos de topografia e cálculos de evaporação, fez a triangulação para estimar as distâncias e confirmou que o lago devia estar conectado a outros mananciais. Sabia da existência de córregos e outros terrenos baldios com possibilidades de nascentes em áreas do entorno do parque; era preciso descobrir de qual deles vinha a água.

Com engenhosidade, Dr. Lobato executou um plano para descobrir por onde a água poderia estar chegando. Só com imaginação um saco de confetes poderia se tornar um recurso de pesquisa. Sua experiência consistiu em jogar um pouco de confete em várias áreas do contorno do lago, até encontrar um ponto que revolvesse os minúsculos círculos de papel. Sempre fotografando, percebeu que em quase toda a extensão das margens da lagoa os confetes boiavam parados, mas que, num certo ponto, eles borbulhavam, sugerindo haver ali uma entrada de água. Iniciou então inspeções para certificar-de de tal possibilidade. Na direção desse ponto de borbulhamento, percebeu uma emenda no cimento do passeio que marginava o lago, como se um cano tivesse sido colocado ali por baixo. Observando bem na grama adjacente, notou um desnível. Seguindo com o olhar em linha reta, descobriu ao fundo, após a extensão do gramado, uma caixa quadrada de cimento. Ao se aproximar, encontrou uma tampa com uma argola. Ao levantar a tampa, 
viu água passando, vinda não se sabe de onde. A água chegava através de uma manilha, e a inclinação da tubulação indicava a possibilidade de pesquisar o seu destino. Os mapas da cidade, como havia constatado, não ajudavam muito. Fez então algumas projeções e seguiu tais coordenadas, atravessando todo o parque, a avenida para a qual se abre o portão principal do mesmo (avenida Afonso Pena), e seguiu por uma rua oblíqua, a rua Pernambuco. Prosseguiu investigando até se deparar com um terreno cercado de muro por todos os lados. Deduziu que a canalização poderia ter origem no interior daquele terreno, uma das poucas áreas ainda não construídas nos arredores.

Começava então uma nova etapa de investigação. Foi até o terreno com - Malheiros. Olharam por uma fresta e perceberam que aquela área não era mais como o mapa indicava. Em vão tentaram encontrar o dono do terreno para solicitar autorização de entrada. Não foi possível evitar um flagrante. Munidos de instrumentos de coleta, encontraram uma estreita passagem e, justamente quando tentavam entrar, foram surpreendidos por um guarda. Uma vez esclarecido o incidente, a noite já caía e Dr. Lobato, de lanterna na mão, passou a inspecionar o terreno. Não demorou muito e encontrou a prova de que precisava. Era uma grande área pantanosa, um atoleiro com plantas aquáticas, um verdadeiro charco. Desvendou um trecho de água mais limpa e percebeu que ali passava uma manilha. Num barranco havia uma caixa. Abrindo-a, encontrou uma nascente, de onde saía a manilha, que passava quase encoberta pela água do charco. Na parte superior da manilha havia uma área quebrada pela qual a água do charco entrava e se misturava à água da nascente. A água do terreno era cheia de caramujos, fezes humanas, restos de comida etc., que contaminavam a água da nascente canalizada até o lago. Dr. Lobato fotografou os caramujos boiando. Com astúcia, imaginou logo um recurso para comprovar, por meio de experiências bem cronometradas, que aquela água chegava ao lago do parque.

No fim de semana, combinou com o Malheiros para voltarem ao local. No bolso do jaleco branco, Dr. Lobato levava um frasco de vidro onde 
reluzia um líquido ainda mais azul do que os seus olhos firmes e confiantes no que estariam provando naquele momento. Explicou com precisão ao estudante que ele deveria derramar todo o conteúdo do vidro, azul de metileno, naquele ponto, marcando a hora exata em que o faria. O líquido, após algum tempo, deveria atravessar a distância que o separava do parque e entraria no lago. Para não deixar dúvidas, pediu ao Malheiros que permanecesse no local, enquanto ele iria para o ponto de entrada da água no lago. Assim que lá chegasse, faria soar um apito, para indicar o momento de derramar o líquido na caixa de entrada da água. Como combinado, cada qual anotou o tempo de saída e chegada do azul de metileno. Toda a seqüência foi fotografada e revelada em slides coloridos, desde o local onde o líquido foi derramado até a sua chegada no lago. Após aguardar um certo tempo, Dr. Lobato viu o filete azul surgir no mesmo ponto em que os confetes borbulhavam, comprovando definitivamente de onde vinham os caramujos que diziam estar ali por encomenda do candidato a prefeito ao pesquisador. Ele ainda usou outros recursos para comprovar a contaminação do lago. Embora os caramujos já pudessem estar parasitados pelo Schistosoma, isto não era suficiente para um percentual tão alto de infecção. Aquele lago parecia uma verdadeira 'boca de latrina'. Dr. Lobato descobriu então que os esgotos dos banheiros do parque também eram despejados no lago. Colocando-se o mesmo corante, o azul de metileno, nos vasos sanitários, bastava acionar as descargas e o azul se alastrava na água do lago.

Após reunir todas essas provas, Dr. Lobato apresentou o trabalho na Associação Médica, o que foi amplamente anunciado pelos jornais. $O$ auditório ficou lotado. O prefeito ainda estava convencido de que tudo não passava de boato dos pesquisadores. Enviou uma equipe e o engenheiro, chefe dos Parques e Jardins. Dr. Lobato apresentou os slides coloridos com desenhos de mapas projetando as tubulações, mostrando a sequiência dos caramujos entrando na manilha, do azul de metileno saindo da manilha e chegando ao lago, assim como o destino das fezes dos banheiros. $\mathrm{O}$ engenheiro enviado pelo prefeito ainda quis insistir em afirmar que tudo 
aquilo não passava de uma montagem dos pesquisadores. Um professor do Departamento de Parasitologia da Universidade Federal de Minas Gerais (UFMG), também no auditório, interrompeu a discussão, perguntando à platéia: "Alguém ainda tem dúvida?" Todos foram unânimes em afirmar que não, além de citarem casos de contaminação entre os filhos dos presentes. Na manhã seguinte, às seis e meia da manhã, os pesquisadores foram chamados para ir rapidamente ao parque. A cena: o prefeito e a equipe esvaziando o lago. Caminhões tirando água. Ao esvaziar tudo, constataram a presença das tubulações descobertas pelo Dr. Lobato. Em seguida, iniciaram obras que incluíram a colocação de placas de concreto no fundo. Rasparam, passaram cal com sulfato de cobre, substância que dá uma tonalidade azul bonita, além de ser tóxica para os moluscos. Foi preciso mais de um mês para encher de novo o lago, agora, sim, saneado como deveria estar desde antes.

\section{Um Engano?}

Certa tarde, o Dr. Lobato examinava rotineira e atentamente alguns exemplares de moluscos coletados em uma expedição feita pelos arredores de Manaus. Minucioso, observava as conchas dos animais para reproduzi-los em desenhos perfeitos, os quais se tornavam guias para a identificação das espécies em suas publicações, consultadas mundialmente. Seus gestos precisos, a leveza da mão, os olhos argutos como os de um cronometrista exibem a sabedoria e a experiência que permitem decifrar enigmas. Sua acurácia e paciência fazem emergir a imagem do relojoeiro de Valparaíso, Dom Astério Alarcón, nos versos de Neruda, ${ }^{5}$ evocando a poesia de quem se entrega à tarefa inundado em curiosidade e sonho.

\footnotetext{
${ }^{5}$ NERUDA, Pablo. Plenos Poderes. Lisboa: Publicações Dom Quixote, 1975.
} 
Como verdadeiro homem de ciência, Dr. Lobato sempre se aplica a cada etapa de seu trabalho como a um desafio sério, ocupando-se de detalhes com atenção e dedicação apaixonada. Assim se achava no laboratório quando notou na concha que examinava um corpo estranho na transparência vazada pelo foco de luz do microscópio. Com uma delicada pinça de relojoeiro, retirou o corpúsculo e, ao examiná-lo na lupa, ficou surpreso. Como aquele animal poderia estar ali? Era uma espécie de molusco pequenino, que as maiores autoridades mundiais da ciência dedicadas ao estudo dos moluscos, os malacologistas, diziam não existir numa vasta área da América do Sul, a qual incluía a região amazônica. Tornou a observar e não duvidou mais: era um autêntico limneídeo. A surpresa acelerou a mente do cientista.

A tarde de novembro caía morna no Rio de Janeiro. Dr. Lobato dirigiu-se rápido ao telefone. Do outro lado atendeu o diretor do Instituto de Pesquisas da Amazônia (Inpa), que não entendia por que o colega ligara de tão longe para perguntar sobre o tempo. É que o Dr. Lobato sabia das chuvas que se iniciam fortes naquela época do ano sobre a região, inundando áreas onde coletara os animais que ora examinava. Se ele não fosse imediatamente investigar melhor sua descoberta, só o faria no ano seguinte, mais de seis meses depois, no próximo período de estio, e então poderia ser tarde demais. Pouco explicou ao diretor sobre suas pretensões, procurou apenas garantir que este o mandasse buscar no aeroporto e lhe fornecesse algum apoio para uma pesquisa de campo, assim como acomodações. Nos minutos que se seguiram, conseguiu o possível e o impossível. Reservou o vôo, solicitou e obteve do então presidente da Fiocruz uma autorização especial para compra imediata de passagens aéreas para aquela mesma noite. Mal teve tempo de se alimentar, arrumar suas coisas, e já estava embarcando para Manaus. Em seu pensamento, as teorias e os fatos envolvidos na evolução das espécies acenavam-lhe com o encontro de mais um elo na cadeia imbricada da especiação e distribuição dos seres vivos no planeta.

Amanhẹceu no Inpa, abrindo suas instalações antes mesmo dos funcionários. Os primeiros a chegar, entusiasmados com a sua presença, 
logo o convidaram a participar de uma reunião de avaliação do instituto, afirmando que ele havia chegado em boa hora. A recusa não foi bem entendida, estranhou a comunidade científica que o recebia tão bem e naquele momento fazia um esforço de auto-avaliação anual. Ninguém suspeitava o porquê da pressa do Dr. Lobato para prosseguir ao campo em sua missão. Afinal, nem ele próprio podia avaliar bem a importância do momento e a iminência da chuva que poderia pôr todo o seu esforço a perder. Dr. Lobato, obstinado, foi em busca de uma viatura disponível para conduzi-lo ao campo. Até as 12 horas parecia não haver nenhum carro, todos já destinados a outras tarefas inadiáveis. Ficou nervoso com tamanho atraso em seus planos; afinal, corria desde a tarde anterior, vencendo inúmeras dificuldades, e não poderia agora esbarrar em um obstáculo desse tipo. Irritado, passou a caminhar pelas dependências do prédio; ao passar por um pátio, avistou um jipe amarelo que, embora envelhecido, parecia bem cuidado. Não hesitou, procurou pelo dono. Era um dos técnicos, que se dispôs a acompanhá-lo caso seu chefe concordasse. Não era preciso dizer que o técnico já estava persuadido da importância da tarefa, tamanha a con vicção com que o cientista o requisitara. $O$ chefe também não se opôs, os argumentos do Dr. Lobato eram imbatíveis. Este, por sua vez, só tinha olhos para o céu, como se desejasse segurar as nuvens cinzentas que, cada vez mais próximas, pareciam atraídas por aquelas bandas.

Chegaram ao local antigo de coleta, de onde o Dr. Lobato havia levado aquelas conchas que examinava no dia anterior. Ali as palafitas se impunham, esculturas esquálidas se equilibrando sobre estacas de quase três metros de altura. Abaixo delas serpenteava uma passarela de pedaços tortos de madeira, simulando uma rua por onde seus moradores transitavam até atingir as escadas bamboleantes que os conduziam à terra firme. Aqueles habitantes das alturas viviam flutuando, ora no ar, ora na água. Afinal, na época das cheias, a água do rio chegava à altura da porta, quando a passarela ficava submersa e o meio de transporte eram os barcos. Dr. Lobato não perdeu tempo, iniciou rastreando os córregos da região, seus antigos conhecidos. 
Munido da velha concha metálica de coleta, ia enchendo os frascos apropriados para armazenar os moluscos, embora ainda não fossem da espécie que fora buscar. A tarde avançava no céu e, com ela, as nuvens cinzentas. De coleta em coleta, chegou a um local admirável. Nem da vez anterior encontrara num único local tamanha densidade de caramujos, e justamente dos que procurava: os limneídeos. Em um recanto, entre luzes e sombras, milhares de diminutas conchas se amontoavam. Seus olhos brilharam de entusiasmo. A alegria energizara seu corpo; sem cansaço algum, abaixou-se quantas vezes foi necessário até encher o quanto pôde os seus reservatórios para transporte dos animais. Era uma bela amostragem, para não deixar qualquer dúvida em seus estudos.

Retornou leve, a flutuar em pensamentos e cheio de motivação para ali voltar no dia seguinte e prosseguir as coletas na vizinhança. Mas eis que, já no Inpa, preparava-se para jantar quando, ainda no banho, ouviu estrondos. $O$ céu disparava $\mathrm{o}$ anúncio da tempestade. A chuva caiu noite adentro, copiosa. No dia seguinte, voltando ao local, o motorista do jipe amarelo assombrou-se com o conhecimento do Dr. Lobato. Como ele afirmara, a água subira sob as palafitas e já ameaçava engolir a passarela. Algumas ampulárias (outra espécie de molusco) boiavam presas à vegetação ambulante, na superfície do imenso rio que avançava. Não era possível encontrar sequer um limneídeo, até o término da cheia. Não tivesse ele chegado naquele dia, e a sua pesquisa poderia não ser concluída. Mas a perspicácia do cientista foi além. Algo mais se revelou a ele mesmo, deixando-o deveras intrigado.

Já em seu laboratório, confortavelmente instalado em sua poltrona de rodinhas, tendo já examinado e comprovado a identificação da espécie de limneídeo encontrada, desenhava sua concha com detalhes de taxionomista experiente que é, quando algo despertou sua mente fértil. Quis rever a concha que o conduzira àquela aventura veloz. Buscou o exemplar cuidadosamente guardado e, para sua surpresa, a dúvida que, repentina, brotava de sua memória concretizou ali um desfecho pouco comum. Aquela 
concha que encontrara escondida dentro de outro animal, agora reobservada, nem de limneídeo era. Na verdade, era um prosobrânquio, já descrito na região, e que, se identificado como tal, não o levaria tão depressa a tão longe. Como ele, conhecedor de moluscos que era, pudera se enganar assim, apenas três tardes antes? Entender como e por que não era possível, mas de uma coisa ele sabia: a descoberta que acabava de fazer mudava bastante o perfil da distribuição dos moluscos na América do Sul e levava a novas e instigantes hipóteses. E se não fosse o constatado engano, nada disso teria acontecido, e a ciência teria de esperar por essa evidência, ou até mesmo não se dar conta dela. Assim, o engano e o tempo em que ocorreu, um dia antes da chuva poder calar as provas, deixam em nosso espírito questões cuja resposta fica limitada a interrogações: engano, intuição, acaso... o que seria? O certo é que há veredas insondáveis nos passos da ciência, nessa caminhada infinita do homem em busca da compreensão de si e do mundo, e o nosso potencial de intuir e criar ainda está muito aquém de ser por nós mesmos entendido.

\section{Três Outras Expedições}

\section{História I}

Dr. Lobato estudava a sistemática dos limneídeos para esclarecer pontos discutíveis, como a distribuição geográfica e os processos de especiação deste grupo de animais. Daquela vez iria em busca de uma espécie pouco conhecida, a Lymnaeadiaphana. Diáfana como o seu próprio nome era a sua existência, atestada pela evidência de um único exemplar. Esse pequeno tesouro estava depositado na coleção malacológica do Museu de História Natural em Londres, coletado em uma remota expedição do Beagle, anterior à expedição de Charles Darwin. Dr. Lobato solicitou o exemplar ao museu britânico, que, considerando a idoneidade e respeitabilidade científica do pesquisador, o enviou ao Brasil. Ele o desenhou em detalhes, reconstituindo 
no papel as características da concha, registrando cada pormenor, e, após devolvê-lo, seguiu em direção ao local onde, conforme indicação, havia sido feita a coleta: Cabo San Gregorio, na Terra do Fogo, uma vírgula de solo no ponto mais estreito do continente sul-americano. Chegar até lá não é uma aventura qualquer: atravessar o continente, em direção à sua porção mais gelada e árida, experimentando os mais variados tipos de transporte.

No lugar, o vento era de $120 \mathrm{Km} / \mathrm{h}$ e a temperatura, de $2^{\circ} \mathrm{C}$. Imagine-se as agruras de fazer coletas em ambiente tão inóspito, tendo os gestos aprisionados em agasalhos pesados e ainda ter de segurar o corpo e proteger o rosto de prováveis queimaduras do vento frio e cortante. Para mergulhar na água a concha metálica perfurada, própria para a coleta de moluscos, era preciso contar com toda a força, pois o vento teimava em querer arrastá-la para bem longe. Ao retirá-la, era necessário proteger rapidamente o material coletado com o corpo e as mãos, senão tudo voaria para longe antes de ser recolhido. Depois de inúmeras tentativas em condições tão adversas, Dr. Lobato conseguiu coletar um único exemplar. $\mathrm{O}$ longo dia de trabalho expirava, deixando um gosto amargo pelo insucesso da coleta. Viajara tanto, para uma terra distante e gelada, para obter tão pouco. Um exemplar era quase nada. Em seus estudos aplicava sempre o princípio da amostragem estatística, a qual requer diversos exemplares para uma avaliação criteriosa por meio da identificação de órgãos internos e características externas. Resolveu caminhar sem rumo certo, seguindo a esmo, sem direção. Ainda não era hora de voltar, ficaria ali até o último rastro de luz no céu. Prosseguiu sem destino; às vezes, sentava-se em algum ponto para descansar, experimentando a solidão e a distância do mundo civilizado. $\mathrm{O}$ conforto de um abrigo, o calor de uma lareira, uma mesa farta eram apenas delírios. Mas qualquer devaneio era um átimo de distração, logo suplantado pela fortaleza do espírito investigador. Descobrir era maior que tudo, e Dr. Lobato prosseguia, o pensamento obstinado da busca fazia submergir até mesmo qualquer desejo ou sofrimento do corpo. Firme em sua intenção, no fim do dia colheu a sua recompensa. Intuindo possibilidades, esgueirou-se 
por um declive estreito, atrás do qual havia um local mais protegido das intempéries típicas do clima daquele lugar. E, ao adentrar essa quase caverna, deparou-se com um amontoado de exemplares Eram mais de trezentos animais, um verdadeiro presente. Assim, pôde coletar um farto material que lhe permitiu realizar com critério os estudos necessários à descrição e caracterização da espécie. Por se tratar de uma vasta área descampada, de paisagem indiferenciada, a escolha da direção deveria ser feita a esmo, sem referências ou pistas. Mas, a firme convicção, a persistência e a observação dos pequenos nichos abrigados como porta-jóias da vida permitiram-lhe sucesso. Embora fique sempre a dúvida: apenas tais elementos talvez não fossem suficientes; era quase como procurar agulha em palheiro, e enorme a chance de caminhar em qualquer outra direção e, conseqüentemente, voltar da cansativa viagem com um único exemplar. Poderíamos falar em sorte? Resposta exata não há, mas o que Dr. Lobato nos lega é a imagem da perseverança, da determinação, da confiança de um espírito preparado e observador. Perseverança que, transformada em plano e ação, pode eventualmente conduzir à descoberta.

\section{História II}

De uma outra vez, um estudo apontava a coleta de uma espécie de Lymmaea na Sierra Oveja, na província de Santa Cruz, Argentina. Dr. Lobato encontrou a informação no quinto volume de uma coleção de registro sobre uma missão à Patagônia, no qual havia a descrição do animal e a indicação do local da coleta, a Sierra Oveja. Nova viagem. Chegando em Buenos Aires, Dr. Lobato procurou o Instituto de Geografia, onde não conseguiu encontrar qualquer indicação de tal local nos detalhados mapas do país. Procurou também no Museu de Paleontologia, pois a coleção indicava fósseis no lugar. Lá, os mapas também não descreviam nenhuma serra com aquela denominação. Foi ao Exército, aos serviços de saúde, procurou um órgão similar à Fundação Nacional de Saúde do país, e nada. Nenhuma referência sobre a Sierra Oveja. 
Decidido, resolveu seguir na direção da Patagônia. De Buenos Aires foi de avião até Rio Gallegos, a última cidade ao sul da Argentina. Lá chegando, convenceu um taxista a conduzi-lo em direção ao pé dos Andes, sempre perguntando, por onde passava, pela tal serra. Nada. Nenhuma informação. Chegou a uma cidade, Gobernador Gregores, onde pernoitou, indagando repetidamente pela serra aos moradores e nativos da região. Ninguém sabia. Na manhã seguinte, seguiu até a uma serra com um nome bem diferente. De qualquer modo, embora sem referência do local, coletou material num riacho ali existente; havia sempre uma possibilidade de encontrar novas espécies. Prosseguiu a viagem. No caminho, parou um motorista de caminhão que também nunca ouvira falar sobre aquela serra. Além disso, 0 motorista recomendou não seguirem adiante, por causa do degelo e do lamaçal da estrada, assim como da inexistência de outros povoados e da impossibilidade de socorro, caso precisassem. Dr. Lobato, a contragosto, retornou, embora sem desistir de seu intento. Desistir nunca foi do seu feitio. Chegando ao Rio, conseguiu no Museu Nacional a coleção inteira dos livros de registro da referida missão e logo no primeiro volume encontrou um mapa da região investigada. Este incluía o mapa da Argentina e a indicação da Sierra Oveja. Copiou o mapa e estudou as coordenadas para projetá-las sobre um mapa atualizado, pois aquele datava de cerca de 1800. Ao fazer a projeção, viu que a cidade de Gobernador Gregores, fundada há apenas cinqüenta anos, estava localizada bem ao pé da Sierra Oveja e que o local onde ele fizera a coleta, o riacho pelo qual passara, era o próprio local da missão. Mais uma vez a persistência, o espírito investigador, a busca levada aos mais ínfimos pormenores permitiram achar a peça que faltava e completar a lacuna do jogo sistemático, como um verdadeiro quebra-cabeça cujas partes estão espalhadas pelo planeta. Reunir tais partes e evidenciar o seu sentido é tarefa que só mesmo verdadeiros missionários abnegados da ciência podem cumprir. 


\section{História III}

Outro fato aconteceu no Chile. Num trabalho de um pesquisador do Museu Nacional de História Natural do Chile, Dr. Walter Biese, estava descrita uma espécie de molusco planorbídeo coletada em uma missão realizada naquele país, num local chamado Cuchicha, situado no deserto de Atacama, descrito em uma das edições da Enciclopédia Britânica como o deserto mais deserto do mundo: "The Atacama desert is the desertest desert in the world". Um deserto onde a vida está ligeiramente pontilhada com solitárias palmeiras que parecem brotar por milagre, em condições tão adversas e de tudo distantes.

Dr. Lobato, incansável, seguiu para o Chile à procura da localização de Cuchicha. Procurou nos museus, nos serviços de geografia, nos da área da saúde, e nada: nenhum registro escrito, e ninguém identificava o lugar. Lembrou-se da fotografia publicada no trabalho do Dr. Biese e reavivou-a em sua memória visual. Recordou que a foto mostrava um pequeno grupo de pessoas que pareciam pontos diminutos, formando uma linha fina em frente a um vulcão. $O$ detalhe do vulcão era um ponto quebrado no cume e uma tênue fumaça saindo para o lado direito. Com a foto na memória, seguiu em direção ao vulcão Ollagüe, próximo à cidade de mesmo nome. Lá chegando, novas dificuldades. Ninguém conseguia identificar um lugar chamado Cuchicha.

Sem revelar a lembrança da fotografia, Dr. Lobato pediu ao motorista da expedição que desse a volta em torno do vulcão, pensando em se colocar na posição em que o pesquisador havia tirado a foto. $O$ veterinário chileno que o acompanhava não podia compreender o motivo de tal solicitação. Dr. Lobato fez segredo, não iria antecipar qualquer suspeita antes de confirmar o que intuía. Seguiram então pela área, sem qualquer estrada, sobre a pavimentação natural de salitre sedimentado. Próximo ao lado em que a fumaça soprava para a direita havia dois penhascos justapostos que, vistos em perspectiva, pareciam uma única pedra. Firme em sua convicção, insistiu para que seguissem adiante. Ao se aproximarem, descortinou-se 
uma passagem de uns três metros entre um penhasco e outro. Para surpresa de todos, avistaram um velhinho caminhando por lá. Num deserto tão distante, encontrar um velho era, certamente, sinal de haver algum povoado próximo. Indagado, o homem os conduziu à passagem, através da qual surgia um povoado de umas quarenta casas. Qual seria o nome do povoado? "Cuchicha", ele respondeu. Lá estava. E como se não bastasse, o velho era o mesmo que trinta anos antes ajudara o pesquisador do Museu Nacional a coletar os caramujos. Era escocês, tinha gosto por coleções e ainda mantinha guardadas as conchas daqueles animais. Mostrou o local da coleta ao Dr. Lobato, que, mais uma vez, obteve material suficiente para o seu almejado estudo. Ali passaram a noite, na casa do velho, e muitas histórias ouviram e contaram. 


\section{Wladimir Lobato Paraense ${ }^{6}$}

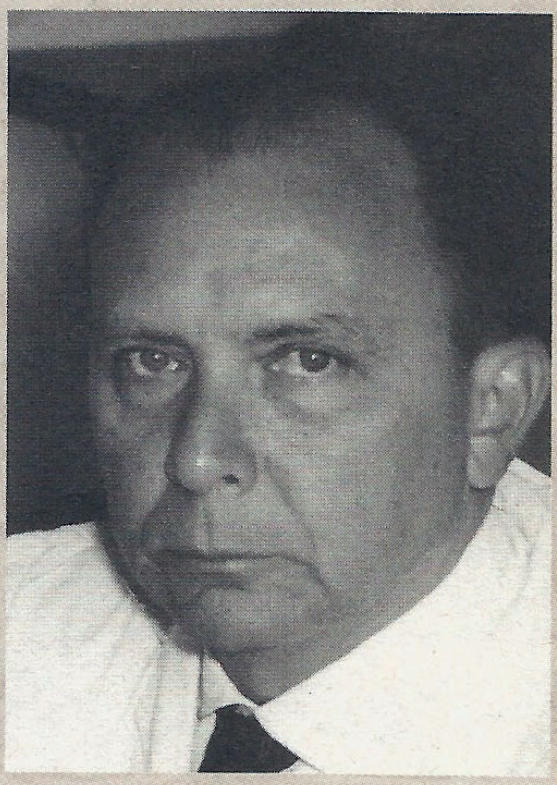

Dr. Wladimir Lobato Paraense é um grande cientista no campo da biologia e medicina, e uma das autoridades mundiais da malacologia, estudo sobre moluscos. Nascido no Pará, na cidade de Igarapé-Mirim em 16 de novembro de 1914, cursou medicina na Faculdade de Medicina e Cirurgia do Pará, tendo completado os estudos na Faculdade de Medicina do Recife, em 1937. Durante 1938 e 1939, fez um curso de especialização em anatomia patológica na Faculdade de Medicina da Universidade de São Paulo. Desde os tempos de estudante trabalhou como auxiliar-acadêmico no Pará e Recife, tornando-se, em 1939, assistente do serviço de Estudo das Grandes Endemias do $10 \mathrm{C}$, onde permanece até hoje, desenvolvendo uma trajetória exemplar como pesquisador. Embora tenha iniciado suas pesquisas relacionadas a aspectos clínicos e epidemiológicos de algumas doenças infectoparasitárias, Dr. Lobato desenvolve desde 1954 um programa de estudos sobre os moluscos e sua classificação biológica. Suas pesquisas permitiram identificar ou diferenciar diversas espécies novas de caramujos, dentre as quais algumas de água doce (planorbídeos), como as Biomphalarias hospedeiras intermediárias do schistosoma mansoni, verme causador da esquistossomose. A distribuição dessa doença, comum em diversas regiões do Brasil, pôde

\footnotetext{
${ }^{6}$ Extraído do currículo cedido pelo pesquisador.
} 
ser melhor estudada depois da diferenciação, demonstrada pelo Dr. Lobato, das três espécies de Biomphalarias vetoras. Dr. Lobato tem contribuído para o avanço do conhecimento no campo da ecologia, da biologia e da reprodução de moluscos, tendo descrito várias novas espécies, identificadas em suas expedições de coleta de animais nos mais variados pontos do planeta. Tem mais de 160 trabalhos científicos publicados e já recebeu diversos prêmios e títulos por sua contribuição à ciência. Seu currículo registra 29 distinções e prêmios: o primeiro, em 1950, foi uma medalha comemorativa do $50^{\circ}$ aniversário do Instituto Oswaldo Cruz; entre os demais destacam-se o Prêmio Golfinho de ouro, na categoria Ciências, do governo do estado do Rio de Janeiro, em 1982; o Prêmio Oswaldo Cruz, da Fiocruz, em 1985; a admissão na Ordem Nacional do Mérito Científico, na Classe Grã-cruz, em 1995; e o título de Man of the Year, em 1997, concedido pelo American Biographical Institute, EUA. Foi também homenageado por pesquisadores que nomearam várias espécies novas com o seu sobrenome. Tem ministrado diversas disciplinas no Brasil e no exterior, orientado a formação e teses de pesquisadores nacionais e internacionais e, como membro de comissões examinadoras, contribuído para o aperfeiçoamento de numerosas teses de mestrado e doutorado. 